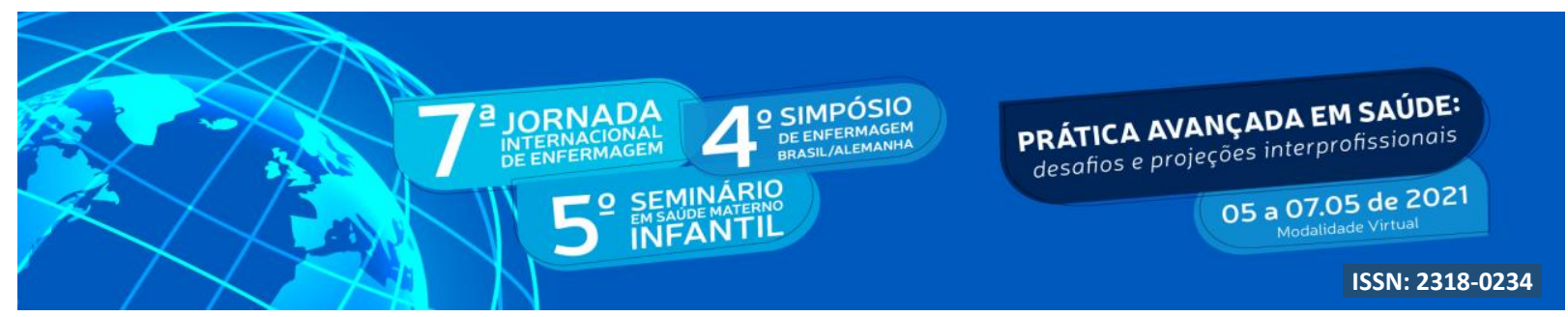

DOI: http://doi.org/10.48195/jie2021-027

\title{
ENFRENTAMENTOS DO ADOLESCENTE COM DOENÇA RENAL CRÔNICA EM HEMODIÁLISE: REVISÃO NARRATIVA DA LITERATURA ${ }^{1}$
}

\author{
Francielle Brum dos Santos de Siqueira ${ }^{2}$; Camila Freitas Hausen ${ }^{3}$; Francielle Morais de \\ Paula $^{4}$; Diúlia Calegari de Oliveira ${ }^{5}$; Aline Ribeiro Cammarano ${ }^{6}$; Eliane Tatsch Neves ${ }^{7}$.
}

\section{RESUMO}

Objetivo: Identificar, na produção científica, os enfrentamentos de adolescentes com doença renal crônica em hemodiálise. Método: Revisão narrativa da literatura, incluindo teses e dissertações nacionais. A busca dos dados foi realizada em julho de 2020, no Banco de Teses e Dissertações da Coordenação de Aperfeiçoamento de Pessoal de Nível Superior (CAPES). Resultados: O medo do procedimento, a barreira social, as modificações na rotina e as transformações físicas são os principais enfrentamentos vivenciados pelos adolescentes em tratamento hemodialítico. A tendência dos estudos está relacionada às mudanças que o tratamento hemodialitico causa na vida dos adolescentes, e referese à mudanças específicas desse período da vida, acrescentados da doença crônica.Conclusões: É pertinente investir em estudos voltados para esse público, uma vez que essa fase é permeada por mudanças significativas na vida dos adolescentes, e às quais influenciam em toda a sua vida o que torna tudo muito intenso com as demandas da insuficiência renal crônica.

Palavras-chave: Adolescente; Doença crônica; Insuficiência renal crônica.

\begin{abstract}
Objective: To identify in scientific production the confrontations of adolescents with chronic kidney disease undergoing hemodialysis. Method: Narrative review of the literature including national theses and dissertations. The search for the data was carried out in July 2020 at the "Banco de Teses e Dissertações da Coordenação de Aperfeiçoamento de Pessoal de Nível Superior (CAPES)". Results: Fear of the procedure, the social barrier and the changes in routine and physical changes are the main confrontations experienced by adolescents undergoing hemodialysis. The trend of studies is related to the changes that hemodialysis treatment causes in the lives of adolescents related to specific changes in this period of life in addition to chronic disease. Conclusions: It is pertinent to invest in studies aimed at this audience since this phase is permeated by significant changes in the lives of adolescents and which they influence throughout their lives which makes everything very intense with the demands of chronic renal failure.
\end{abstract}

Key Words: Adolescent; Chronic disease; Renal insufficiency, chronic.

\footnotetext{
${ }^{1}$ Estudo de revisão narrativa da literatura, incluindo teses e dissertações nacionais.

${ }^{2}$ Enf $^{a}$ Mestranda, Universidade Federal de Santa Maria; francisbrum@gmail.com

${ }^{3}$ Enf $^{a}$ Mestranda, Universidade Federal de Santa Maria; camilafht@@hotmail.com

${ }^{4}$ Enf $^{a}$ Mestranda, Universidade Federal de Santa Maria; fraanmdepaula@gmail.com

${ }^{5}$ Acadêmica do curso de Enfermagem, Universidade Federal de Santa Maria; diuliacoliveira@gmail.com

${ }^{6}$ Coorientadora. Enf ${ }^{a}$ Dra, Universidade Federal de Santa Maria; alinecammarano@ gmail.com

${ }^{7}$ Orientadora. Enf ${ }^{a}$ Dra, Universidade Federal de Santa Maria; eliane.neves@ ufsm.br
} 


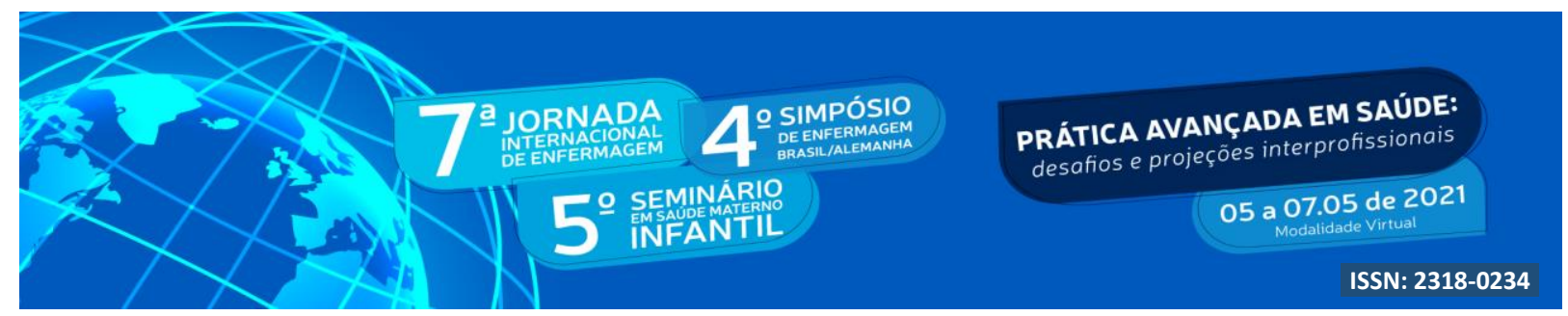

\section{INTRODUÇÃO}

A adolescência é considerada um período de transição entre a infância e a fase adulta. Marcado pelo amadurecimento físico, cognitivo, social e emocional. E, a juventude é balizada pela transição da adolescência para a vida adulta, uma fase de preparação. Sendo assim os adolescentes e os jovens vivenciam modificações marcantes, tanto corporais, característicos da puberdade, como mudanças na esfera psicossocial. (HOCKENBERRY; WILSON, 2014 e SILVA, SILVA, 2011). A adolescência, do Latim "adolescentia", nas civilizações do mundo ocidental, como Roma e Grécia Antiga, não possuíam uma percepção clara dessa transição. Os jovens eram condicionados pelo governo da época a treinar e obedecer, sem opções de possuírem ambições ou desejos. O entendimento que possuímos hoje como adolescência só começou a ser delineado no século XVII. (LIRA; SILVA, 2017).

As doenças crônicas são marcadas por um grupo de condições crônicas, permeadas por um prognóstico incerto, podendo ter duração longa ou indefinida, necessitando de um cuidado contínuo, e muitas vezes sem resultado de cura (BRASIL, 2013). As doenças crônicas em adolescentes determinam modificações no seu cotidiano, além de restrições causadas pela própria doença, que exigem constantes cuidados e adaptações a essa nova situação (ARAÚJO et al, 2020). Na maioria das vezes, a Doença Renal Crônica (DRC) acontece após a injúria renal seguida de perda lenta, progressiva e irreversível da função renal. O diagnóstico nos grupos de risco é avaliado por um teste laboratorial chamado clearance de creatinina sérica, caracterizado pela presença de microalbuminúria, proteinúria, hematúria e na redução do ritmo de filtração glomerular (RIELA, 2018).

A DRC está entre as patologias que acometem adolescentes, sendo uma doença de evolução progressiva, trazendo mudanças e limitações, podendo gerar conflitos sociais e psicológicos (RÊGO; MARTINS; SALVIANO, 2019). E, uma doença crônica como a Insuficiência Renal Crônica (IRC), estabelece limitações e mudanças significativas na vida dos adolescentes, causando não apenas desequilíbrios no organismo, mas também impacto nas relações sociais e com seus pares (SOUZA; MELO, 2018).

Nessa perspectiva, este estudo justifica-se por incluir-se na Agenda 2030 pois 


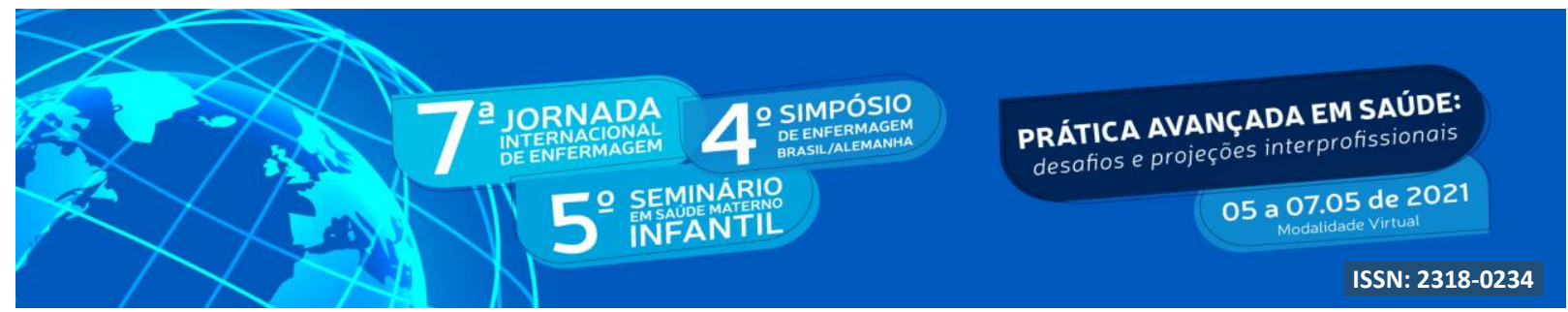

apresenta os Objetivos de Desenvolvimento Sustentável (ODS). Sendo que um desses objetivos é assegurar uma vida saudável e promover o bem-estar para todos, em todas as idades, e tendo como uma das suas metas reduzir em um terço a mortalidade prematura por doenças crônicas não transmissíveis via prevenção e tratamento até 2030 (ONU, 2015). Salienta-se que essa meta, vem fortalecer a importância do avanço das doenças crônicas. Além disso, a temática em questão é referenciada na Agenda Nacional de Prioridades em Pesquisa em Saúde pelo Ministério da Saúde (MS), na qual são priorizados estudos referentes ao público adolescente, com destaque para o acesso dos adolescentes nos serviços de saúde e nas oportunidades perdidas de orientação, informação e prevenção de fatores de risco na adolescência causado pelo afastamento destes dos serviços de saúde (BRASIL, 2015).

\section{OBJETIVO}

Identificar, na produção científica, os enfrentamentos de adolescentes com doença renal crônica em hemodiálise.

\section{METODOLOGIA}

Trata-se de um estudo de revisão narrativa da literatura, incluindo teses e dissertações nacionais. A busca dos dados foi realizada em julho de 2020, no Banco de Teses e Dissertações da Coordenação de Aperfeiçoamento de Pessoal de Nível Superior (CAPES), buscando-se: adolescente* AND “insuficiência renal” resultando em 89 registros.

Este estudo foi organizado de acordo com as seguintes etapas: escolha do tema, formulação da pergunta de pesquisa, seleção dos critérios de inclusão, formulação de estratégia de busca, testagem exaustiva de diferentes estratégias de busca a fim de obter um corpus de amostra representativo, realização da busca, extração dos dados, análise e categorização dos resultados.

Os critérios de inclusão foram: teses e dissertações sobre adolescentes com insuficiência renal, independentemente da linha de pesquisa ou área de conhecimento. Os critérios de exclusão foram: estudos que abordassem crianças e estudos com resumo 


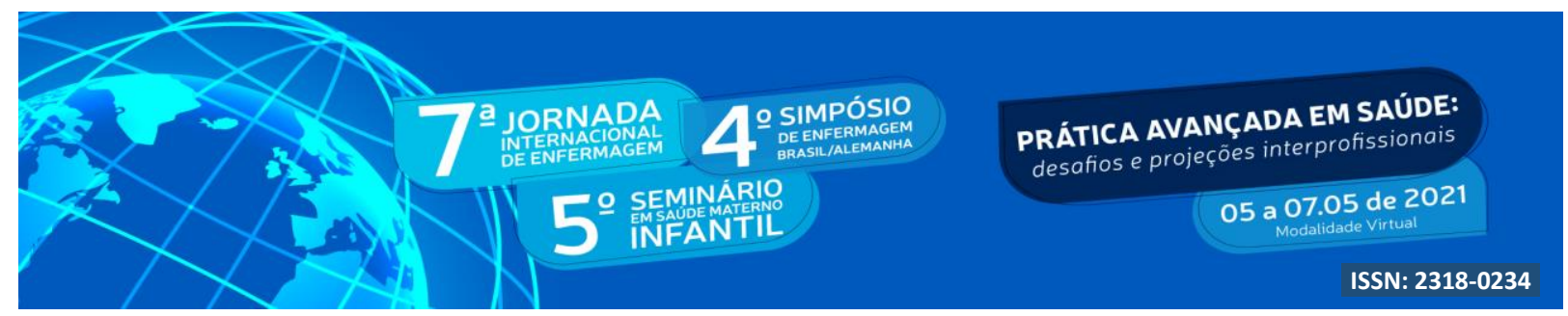

incompletos ou não disponível no banco de dados. Não foi estabelecido recorte temporal para esta seleção. Os títulos e resumos foram acessados na plataforma CAPES. Após a busca, foram aplicados os critérios de inclusão, partindo da leitura dos títulos e resumos. Foram excluídos 81 estudos que não estavam relacionados à temática, estudos com adultos, transplantados renais e estudos que abordavam crianças. Dos 8 estudos selecionados, 1 precisou ser excluído devido não ter sido encontrado, o trabalho completo e o resumo. Restando sete estudos, lidos na íntegra, os quais foram incluídos para esse trabalho. Destacase que o estudo que não foi encontrado disponível na íntegra só foi excluído após tentativa de contato com o autor e com a biblioteca, solicitando cópia na íntegra, sem sucesso em ambas tentativas.

A Figura 1 apresenta o fluxograma para a seleção dos estudos.

Figura 1: Fluxograma da seleção dos estudos sobre os enfrentamentos de adolescentes com doença renal crônica em hemodiálise.

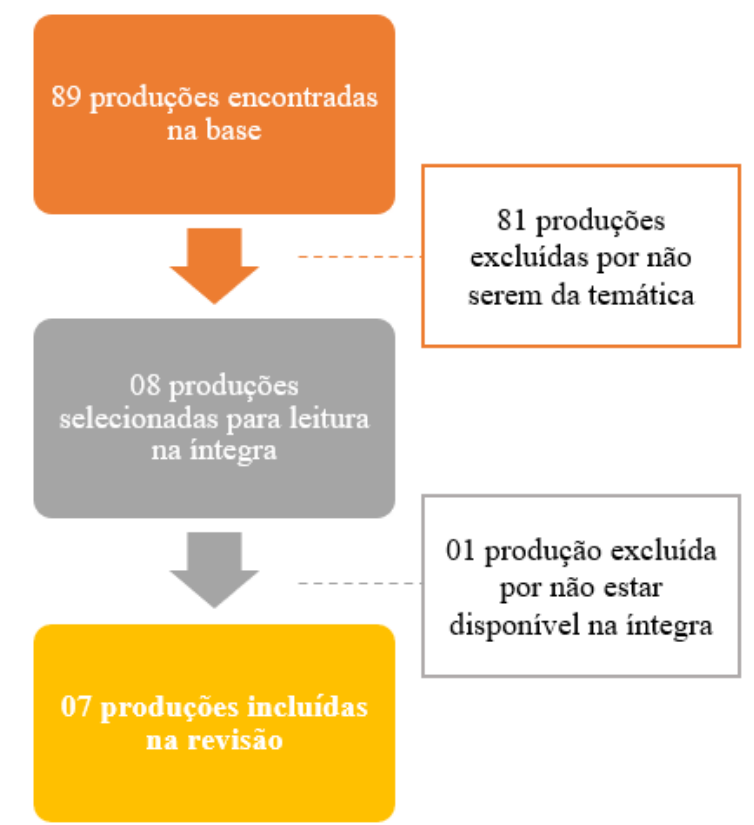

Fonte: elaborado pelas autoras

Quadro 1: Teses e Dissertações selecionados. Santa Maria, 2020. 


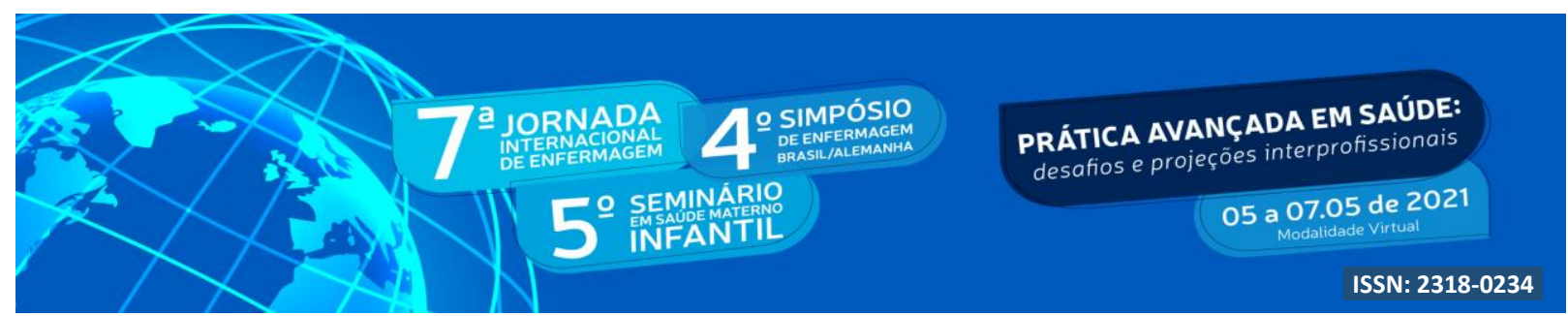

\begin{tabular}{|c|c|c|c|c|c|}
\hline ID & Título & Autor/Ano & Categoria & Instituição & Área \\
\hline 01 & $\begin{array}{l}\text { A Subjetividade do } \\
\text { Adolescente Acometido } \\
\text { de Insuficiência Renal } \\
\text { Crônica. }\end{array}$ & $\begin{array}{l}\text { RIBEIRO, S. } \\
\text { K.M; } 2003 .\end{array}$ & Dissertação & $\begin{array}{c}\text { Faculdade de } \\
\text { Medicina. } \\
\text { Universidade } \\
\text { Federal do Ceará, } \\
\text { Fortaleza. } \\
\end{array}$ & Medicina \\
\hline 02 & $\begin{array}{l}\text { Adolescência: época de } \\
\text { metamoforse e uma } \\
\text { doença inesperada - Um } \\
\text { Estudo Sobre o Cuidado } \\
\text { de Enfermagem ao } \\
\text { Adolescente em } \\
\text { Tratamento } \\
\text { Hemodiálico. }\end{array}$ & $\begin{array}{c}\text { NUNES, } \\
\text { A.S.; } 2003 .\end{array}$ & Dissertação & $\begin{array}{c}\text { Universidade } \\
\text { Federal do estado } \\
\text { do Rio de } \\
\text { Janeiro. }\end{array}$ & Enfermagem \\
\hline 03 & $\begin{array}{l}\text { Representações sociais } \\
\text { dos adolescentes em } \\
\text { situação de Doença renal } \\
\text { crônica sobre o } \\
\text { Adoecimento e o } \\
\text { cuidado. }\end{array}$ & $\begin{array}{c}\text { RAMOS, I.C.; } \\
2007 .\end{array}$ & Dissertação & $\begin{array}{c}\text { Universidade } \\
\text { Estadual Do } \\
\text { Ceará, Fortaleza. }\end{array}$ & Enfermagem \\
\hline 04 & $\begin{array}{l}\text { Promoção da saúde } \\
\text { mental de adolescentes } \\
\text { renais crônicos: a } \\
\text { tecnologia leve como } \\
\text { cuidado de Enfermagem. }\end{array}$ & $\begin{array}{c}\text { RAMOS, I.C.; } \\
2013 .\end{array}$ & Tese & $\begin{array}{c}\text { Faculdade de } \\
\text { Farmácia, } \\
\text { Odontologia e } \\
\text { Enfermagem da } \\
\text { Universidade } \\
\text { Federal do Ceará. }\end{array}$ & Enfermagem \\
\hline 05 & $\begin{array}{l}\text { Em busca da } \\
\text { normalidade: Sendo-com } \\
\text { adolescentes com } \\
\text { insuficiência renal } \\
\text { crônica. }\end{array}$ & $\begin{array}{l}\text { SOUZA, } \\
\text { M.A. de; } \\
2014 .\end{array}$ & Dissertação & $\begin{array}{l}\text { Universidade } \\
\text { Estadual De } \\
\text { Campinas. }\end{array}$ & Enfermagem \\
\hline 06 & $\begin{array}{l}\text { O adolescente lutando } \\
\text { para que a hemodiálise } \\
\text { não o defina: } \\
\text { corporeidade, identidade } \\
\text { e estigma. }\end{array}$ & $\begin{array}{l}\text { MIETO, F. S. } \\
\text { R.; } 2018 .\end{array}$ & Tese & $\begin{array}{c}\text { Escola de } \\
\text { Enfermagem da } \\
\text { Universidade de } \\
\text { São Paulo. }\end{array}$ & Enfermagem \\
\hline 07 & $\begin{array}{l}\text { Insuficiência } \\
\text { Renal crônica na } \\
\text { Pré-adolescência e } \\
\text { Adolescência: } \\
\text { experiências de } \\
\text { Pacientes, mães e } \\
\text { médicos. }\end{array}$ & $\begin{array}{l}\text { SILVA, B. B.; } \\
2019 .\end{array}$ & Dissertação & PUC Campinas & Psicologia \\
\hline
\end{tabular}

Fonte: Plataforma CAPES. Elaborada pelas autoras. 


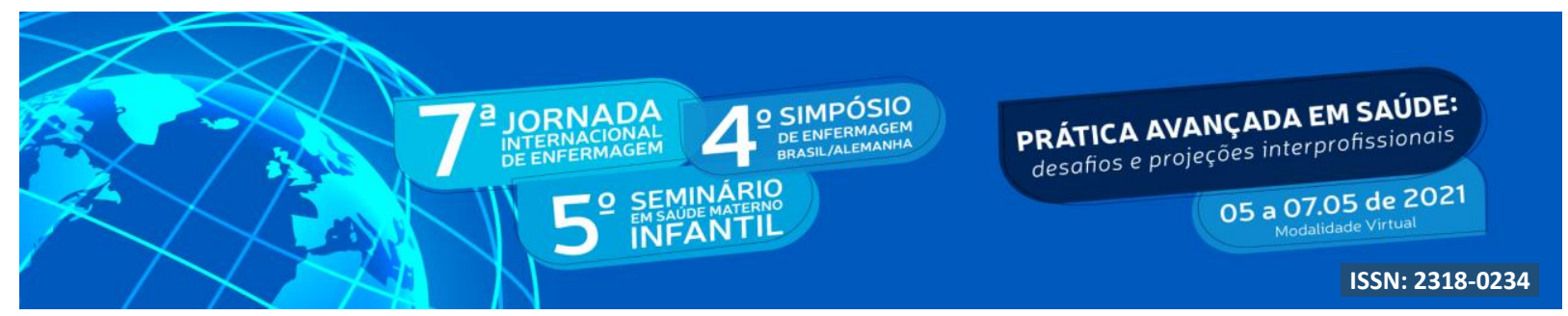

\section{Caracterização das produções}

Quanto à modalidade do programa de pós-graduação, identificou-se que dos 7 estudos selecionados 02 são teses - Doutorado em Enfermagem, 03 são dissertações - Mestrado em Enfermagem, 01 de Mestrado em Psicologia e 01 de Mestrado em Saúde Pública.

Referente a abordagem metodológica, evidenciou-se predomínio de estudos qualitativos totalizando 04, e estudos quali-quantitativos com 03. Em relação às instituições de ensino, destacaram-se os estados do Ceará e de São Paulo com 3 estudos cada um e 1 estudo no Rio de Janeiro.

\section{RESULTADOS E DISCUSSÃO}

Os estudos apontaram que o medo do procedimento, a barreira social, as modificações na rotina e as transformações físicas são enfrentamentos vivenciados pelos adolescentes em tratamento hemodialítico (FIG. 1). O adolescente em hemodiálise além das mudanças na rotina, vivencia a presença do medo relacionado ao procedimento e as intercorrências que podem surgir durante a realização do tratamento (RÊGO, MARTINS, SALVIANO, 2019). Também, a rotina do tratamento dialítico exige determinação e disciplina resultando em afastamento das relações interpessoais e dos grupos comuns a faixa etária dos adolescentes e jovens. Ocasionando assim, comumente, o isolamento social dos seus pares (SILVA, SILVA, 2011). Ainda, o adolescente em hemodiálise tem sua rotina modificada, necessitando de uma nova adequação frente ao tratamento. Os adolescentes necessitam realizar as sessões de hemodiálise, que duram em média de quatro horas, cerca de três vezes por semana, o que favorece o isolamento social, e também leva a necessidade de uma readaptação por parte da família dos adolescentes em tratamento. E, em alguns casos a doença pode afetar a qualidade de vida da pessoa de maneira intensa (BONASSI, NAVARRO, 2018). Há ainda, às restrições físicas e alimentares, além de muitas vezes terem dificuldades com a frequência escolar, devido a própria doença, hospitalizações e efeitos colaterais dos medicamentos. Além disso, há o conflito interno de contar aos colegas sobre sua doença e o tratamento que precisa realizar, podendo gerar o medo de assim receber um tratamento diferenciado por ter uma doença crônica (RÊGO, MARTINS, SALVIANO, 2019). Soma-se a isso as mudanças relacionadas ao aspecto físico. Adolescentes que vivenciam a hemodiálise podem sofrer com 


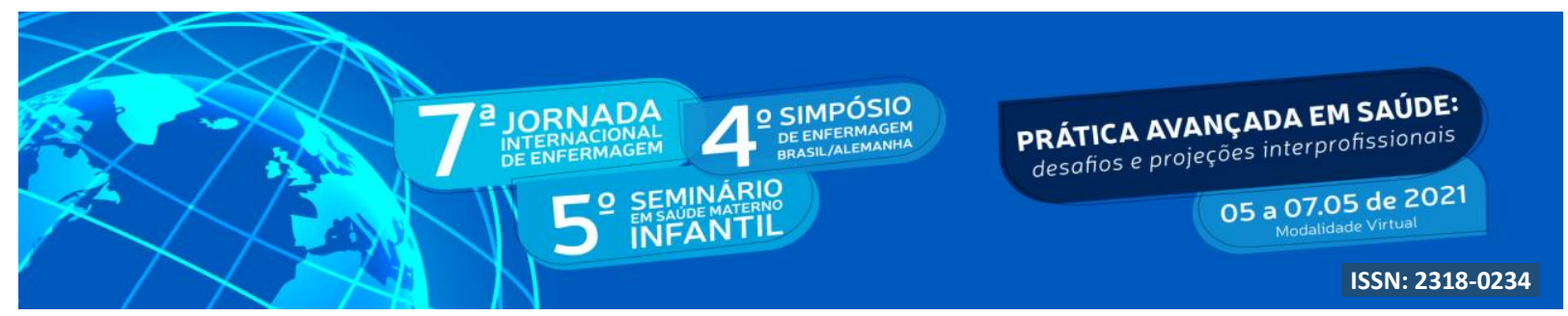

as alterações de sua autoimagem, com a insatisfação corporal e autoestima, devido às mudanças corporais decorrentes do uso do cateter ou fístula, principalmente em relação a fístula arterio-venosa, que pode ocasionar cicatrizes e aneurismas na região (SOUZA et al,2019). Uma vez que nessa fase de vida muitas vezes já existe um conflito de imagem por parte do adolescente, marcado por mudanças físicas e emocionais, pontuadas por descobertas e influências que repercutiram no processo de formação da pessoa, marcado por alterações cognitivas, sociais e de perspectiva sobre a sua própria identidade (RÊGO, MARTINS, SALVIANO, 2019). Procedimentos invasivos, sintomas da doença, desconforto físico, efeitos secundários de medicações e do tratamento, que ocasionam transformações e mudanças físicas, além da eventualidade de uma diminuição na expectativa de vida, são enfrentamentos vivenciados por esses adolescentes (SILVA; SILVA, 2011).

A adolescência é marcada por transformações, as quais geram medo e insegurança. Diante disso ainda há o enfrentamento da doença, do novo e do desconhecido, podendo aumentar ainda mais a insegurança vivida pelos adolescentes. Soma-se a isso as restrições e limitações causadas pela doença, implicando muitas vezes em um afastamento do seu grupo social.

A figura 2 apresenta os principais resultados encontrados no estudo de revisão.

Figura 2: Principais resultados encontrados no estudo de revisão narrativa.Santa Maria, Brasil,2020.

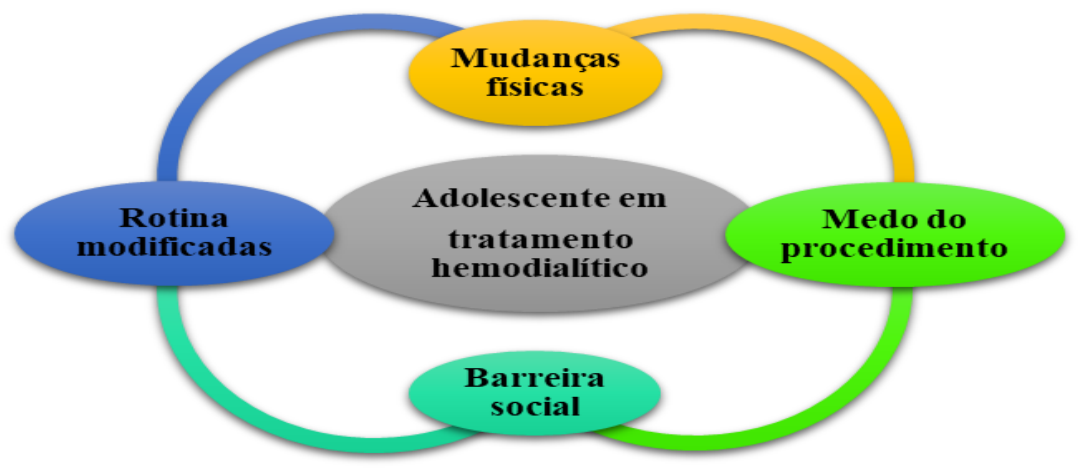

Fonte: Elaborada pelas autoras.

\section{CONCLUSÃO}

Conclui-se que os enfrentamentos dos adolescentes estão relacionados às mudanças 


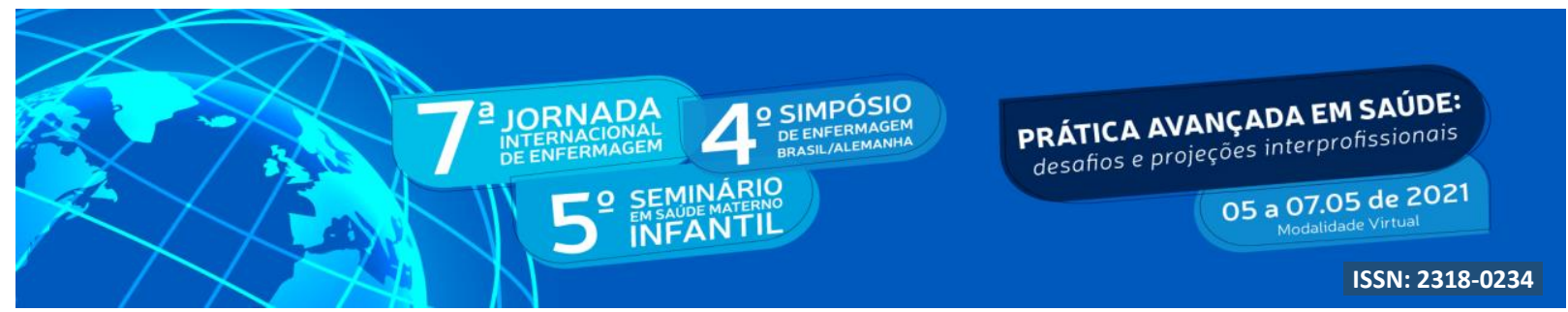

que o tratamento hemodialítico causa em suas vidas, os quais além de perpassarem pelas mudanças específicas da fase, possuem especificidades de conviver com uma doença crônica. Tais mudanças citadas são relacionadas a questões físicas, emocionais, rotina diária modificada e ao convívio com seus pares. Destaque-se a relevância de investimentos em estudos voltados para esse público especificamente, uma vez que essa fase é permeada por mudanças significativas na vida dos adolescentes, que ainda estão se adaptando às mudanças relacionadas com as demandas da Insuficiência Renal Crônica.

\section{REFERÊNCIAS}

ARAUJO, Y. B.; et al . Modelo preditor de internação hospitalar para crianças e adolescentes com doença crônica. Rev. Bras. Enferm., v. 73, n. 2, e20180467, 2020 .

BONASSI, S.; NAVARRO, R. S. Doença renal crônica: fronteiras e desafios familiares. VINCULO -Revista do NESME., v.15, n.1, p. 48-60, 2018.

BRASIL. Ministério da Saúde, Secretaria de Atenção à Saúde. Documento de diretrizes para o cuidado das pessoas com doenças crônicas nas Redes de Atenção à Saúde e nas linhas de cuidado prioritárias. Brasília: MS; 2013. [Citado em 05 Março 2021]. Disponível em:https://bvsms.saude.gov.br/bvs/publicacoes/diretrizes\%20_cuidado_pessoas\%20_doencas _cronicas.pdf.

. Ministério da Saúde. Agenda Nacional de Prioridades de Pesquisa em Saúde. Série B. Textos Básicos em Saúde. Brasília (DF): Editora do Ministério da Saúde, 2015. [Citado em 05 Março 2021]. Disponível em: http://bvsms.saude.gov.br/bvs/publicacoes/agenda_nacional_prioridades_2ed_4imp.pdf

HOCKENBERRY, M. J.; WILSON, D. WONG. Fundamentos de enfermagem pediátrica. 9. ed. Rio de Janeiro: Elsevier, 2014.

LIRA, D. M. B.; SILVA, R. C. A. Adolescência - Quando surgiu e para onde vai?Um Recorte Histórico e Psicossocial. Revista Latino-Americana De Psicologia Corporal., v. 6, n. 1, p.42-52, 2017 .

ONU BR - NAÇÕES UNIDAS NO BRASIL - ONU BR. A Agenda 2030, 2015. [Citado em 08 Março 2021]. Disponível em: https://nacoesunidas.org/pos2015/agenda2030/

RÊGO, L. W.; MARTINS, G., SALVIANO, C. F. Impacto da doença renal crônica em adolescentes em tratamento hemodialítico. Rev.enferm UFPE on line., v.13, n. e240286, 2019. 


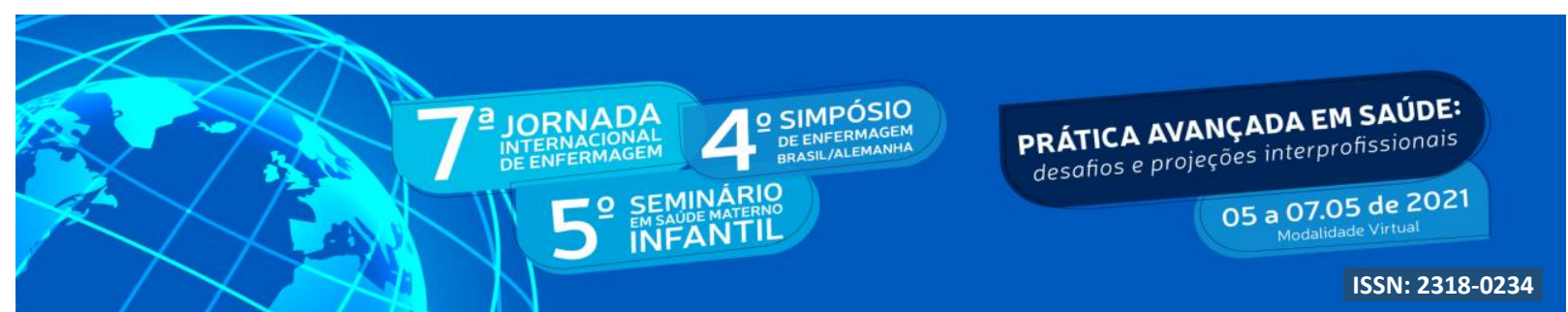

RIELLA, M. C. Princípios de nefrologia e distúrbios hidroeletrolíticos. 6. ed. Rio de Janeiro: Guanabara Koogan, 2018.

SILVA, E. M. S.; SILVA, L. W. S. Impacto da hemodiálise na vida de adolescentes acometidos pela insuficiência renal crônica. Rev. Adolesc Saude., v. 8, n.1, p.43-50, 2011.

SOUZA, M. A.; MELO, L. L. Ser adolescente com insuficiência renal crônica: um olhar por meio da fenomenologia existencial. Esc. Anna Nery., v. 22, n. 2, p.1-8, 2018.

SOUZA, T. T.; et al. Impactos da Doença Renal Crônica no desempenho ocupacional de crianças e adolescentes em hemodiálise. Cad. Bras. Ter. Ocup., v. 27, n. 1, p.72-80, 2019. 